\title{
Thalassoterapi uygulamaları için kültür koşullarında yetiştirilen makroalglerin vitamin kompozisyonunun belirlenmesi
}

\section{Determination of vitamin composition of cultured macroalgae for Thalassotherapy applications}

\author{
Gamze Turan* ${ }^{\text {D }}$ Semra Cirik \\ Ege Üniversitesi, Su Ürünleri Fakültesi, Yetiştiricilik Bölümü, 35100 Bornova, İzmir, Turkey \\ *Corresponding author: gamze.turan@ege.edu.tr
}

\footnotetext{
How to cite this paper:

Turan, G. \& Cirik, S. (2018). Determination of vitamin composition of cultured macroalgae for Thalassotherapy applications. Ege Journal of Fisheries and Aquatic Sciences, 35(2), 151-156. DOI:10.12714/egejfas.2018.35.2.07
}

\begin{abstract}
Öz: Bu çalışmada, Thalassoterapi'de kullanım potansiyelini belirlemek amacıyla sularımızda doğal olarak dağılım gösteren makroalg türlerimizin (Ulva rigida, Gracilaria gracilis, Sargassum vulgare, Cystoseira barbata ve Dictyopteris membranacea) kültür koşullarında vitamin kompozisyonları belirlenmiştir. Vitamin analiz sonuçları alglerin $\beta$-karoten (provitamin A), askorbik asit (vitamin $\mathrm{C}$ ) ve $\alpha$ - tokoferol (vitamin $\mathrm{E}$ ) yönünden zengin olduğunu göstermektedir. $\beta$-karoten (provitamin A) yönünden en zengin $3.25 \pm 0.41 \mathrm{mg} .100 \mathrm{~g}^{-1}$ miktarıyla Gracilaria gracilis bulunurken vitamin $\mathrm{C}$ (askorbik asit) yönünden en zengin $7.42 \pm 0.67$ mg.100 $\mathrm{g}^{-1}$

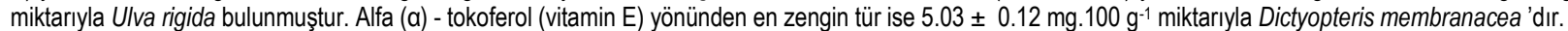

Anahtar kelimeler: Algler, Akvakültür, Deniz terapisi, SPA, Yosun uygulamaları

Abstract: In this study, vitamin compositions were determined in culture conditions of macroalgae (Ulva rigida, Gracilaria gracilis, Sargassum vulgare, Cystoseira barbata and Dictyopteris membranacea) which are naturally distributed in our waters in order to determine their potential usage in Thalassotherapy. The results of vitamin analysis show that the algae are very rich in terms of $\beta$-carotene (provitamin A), ascorbic acid (vitamin $C$ ) and $\alpha$-tocopherol (vitamin $E$ ). According to the results, it was found that Gracilaria gracilis is the richest species in terms of $\beta$-carotene (provitamin A) with the amount of $3.25 \pm 0.41 \mathrm{mg} 100 \mathrm{~g}{ }^{-1}$, Ulva rigida is

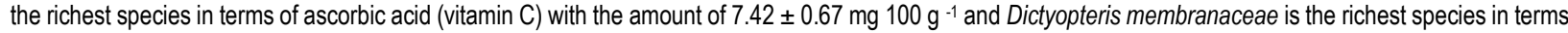

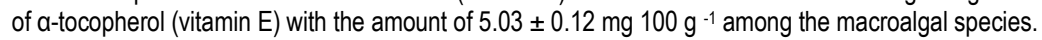

Keywords: Algae, Aquaculture, Sea therapy, SPA, seaweed applications

\section{GíRiş}

İçinde kremlerin ve losyonların da dahil olduğu çeşitli güzellik ve kozmetikle ilgili ürünlerin üzerindeki etiketlere bakıldığında "deniz özleri" "yosun özleri" "alg özleri" veya benzeri yazılar görülmektedir. Genellikle bu tip açıklamalar alglerden elde edilen değerli hidrokolloidlerden en az birinin ürünün içinde bulunduğunu gösterir. Aljinat veya karragen güzellik ürününün cilt nemini dengeleme özelliğini sağlar. Ezme veya dondurarak parçalama yöntemleriyle macun haline getirilen algler Thalassoterapi'de kullanılır. Deniz Terapisi anlamına gelen Thalassoterapi, deniz suyunun, alglerin, çamurun, kumun ve deniz havasının insan sağlığı ve güzelliğ için özel merkezlerde sağlık uzmanlarının kontrolü altında yapılan bir tedavi yöntemidir (De Roeck-Holtzhauer, 1991).

Thalassoterapi'nin, çoğu zaman termal su terapisi, fizyoterapi veya SPA terapi uygulamalarıyla aynı olduğu düşünülmektedir. Oysa termal su merkezlerinde hastalıkların tedavisi sırasındaki banyo, duş, çamur ve yosun uygulamaları (c) Published by Ege University Faculty of Fisheries, Izmir, Turkey esnasında sadece kaynak suları kullanırken, Thalassoterapi kürleri için sadece deniz suyu kullanılır (Donadieu ve Basire, 1985; Boisvert, 1988; De Roeck-Holtzhauer, 1991; Cirik, 2005).

Fizyoterapi'den farklı olarak Thalassoterapi deniz kıyısında, özellikle travma ve ameliyatlar sonrası meydana gelen rahatsızlıkları ve engellilerde görülen ağrıların tedavisinde uygulanır. Thalassoterapi'de uygulanan tedavi hastanelerdeki terapötik protokolle aynıdır. SPA'larda uygulanan tedavi esnasında ise verdiği hafiflik hissi nedeniyle evlerimizde bulunan çeşme suları kullanılır. Thalassoterapi kadar, popüler adıyla SPA'lar günümüzde sağlık ve güzellik merkezlerinin vazgeçilmez parçaları halini almaktadır (Cirik, 2005).

Thalassoterapi merkezlerinde tıbbi ve sağlık amaçılı alglerin kullanıldığı programlar arasında, kilo verme, cilt ve vücut sıkılaştırma, selülit, stres, toksinlerden arınma (detoks), 
dolaşım bozukluklarının giderilmesi, vücut enerjisinin yeniden dengelenmesi, depresyon, spor yaralanmaları, osteoporoz, menapoz, sürmenaj, sigara bırakma ve doğum sonrası yenilenme ve sıkılaşma, sunulan kürlerden bazılarıdır (Donadieu ve Basire, 1985; Boivert, 1988; De RoeckHoltzhauer, 1991; McHugh, 2003; Cirik, 2005; Cirik ve Turan, 2003).

Alglerin Thalassoterapi'de kullanımı tedavilerin başarısında büyük bir rol oynar. Çünkü zengin mineral ve vitamin içeriklerinden dolayı algler eşsiz sağlık kaynaklarıdır. İnsan vücudu canlılığını sürdürebilmek için mineral maddelere ve vitaminlere intiyaç duyar. Kalsiyum, magnezyum, sodyum, potasyum gibi mineraller, demir, bakır, çinko ve mangan gibi iz elementler ve tüm vitaminler alglerin yapılarında bulunmaktadır. Bir alg türünün Thalassoterapi için değerinin saptanmasında dikkat edilen en önemli faktör içeriğinin zenginliğidir (De Roeck-Holtzhauer, 1991).

Pudra veya macun halinde hazırlanan algler Thalassoterapi Merkezlerindeki kürler esnasında uygulanır. Laminaria digitata, Fucus vesiculosus ve Lithothamnion corallioides yaygın olarak kullanılan makroalg türleri olmasına rağmen Thalassoterapi ürünlerine her geçen gün yeni alg türleri eklenmektedir. Alglere olan ilginin sürekli artması, mineral ve vitaminlere ek olarak çok değerli ve orijinal yapıların alglerde tespit edilmesiyle açıklanmaktadır. Değerli ürünlerin arasında proteinler, pirolik yapılar, fenoller, arseno şekerler, fufosterol gibi steroller, kondrin, gigartinin ve kainik asit gibi amino asitler, kırmızı alglerden elde edilen fikoeritrin, kahverengi alglerden elde edilen ksantin, ve mavi-yeşil alglerden elde edilen fikosiyanin gibi pigment maddeleri sayılabilir (Cirik, 2005).

Ülkemizde Thalassoterapi merkezlerinin sayısı ve programları hızla gelişmektedir. Sağlık ve güzellik için doğal formüller arayan kişiler Thalassoterapi merkezlerine seyahat ederek turizm sektörüne de önemli katkılar sağlamaktadır. Thalassoterapi merkezlerinde kullanılan alg bazlı ürünler yüksek fiyatlardan ülkemize ithal edilmektedir. Halbuki ürünler içindeki alg türleri veya eşdeğerleri ülkemiz sularında mevcuttur (Cirik ve Turan, 2003). Denizlerimizdeki makroalg türleri üzerinde bugüne değin yapılan araştırmalarda denizel floranın 1,000 kadar türden oluştuğu saptanmıştır (Cirik, 1978; Cirik vd., 1988; Cirik vd., 2001; Cirik vd., 2006; Cirik ve Cirik, 2017).

Türkiye'de Thalassoterapi amaçlı yosunlara dayalı bir sanayi henüz gelişmemiş olmasına rağmen Thalassoterapi ve SPA, latince adıyla "Senus Per Aquam" yani su'dan gelen sağlık, sektörünün gelişimine paralel olarak önümüzdeki yıllarda deniz bitkilerinin yetiştiriciliği ve bu bitkilere yönelik sanayinin gelişip yaygınlaşacağı düşünülmektedir (Ak ve Cirik, 2017).

$\mathrm{Bu}$ çalışmada, ülkemiz koşullarında üretimin ve Thalassoterapi'de kullanım potansiyelini belirlemek amacıyla sularımızda doğal olarak dağıım gösteren makroalg türlerimizin (Ulva rigida, Gracilaria gracilis, Sargassum vulgare, Cystoseira barbata ve Dictyopteris membranacea) vitamin kompozisyonları belirlenmiştir. Sonuçlar THALGO firmasının aynı isimle piyasada yer alan ürünün analiz sonuçları ile karşılaştııllarak sunulmuştur. THALGO ürünleri içerisinde bulunan algler Laminaria digitata, Fucus vesiculosus ve Lithothamnion corallioides türlerinden oluşmaktadır.

\section{MATERYAL VE METOT}

Yeşil makroalglerden Ulva rigida, kırmızı makroalglerden Gracilaria gracilis ve kahverengi (esmer) makroalglerden Sargassum vulgare, Cystoseira barbata ve Dictyopteris membranacea bu araştırmada üzerinde çalışılan makroalg türleridir.

\section{Makroalglerin toplandığı istasyonlar}

Ulva rigida ve Gracilaria gracilis bol bulundukları ilkbahar aylarında İzmir Körfezi Bostanlı İskelesi civarından ve Sargassum vulgare, Cystoseira barbata ve Dictyopteris membranacea yaz aylarında Urla-İskele sahillerindeki çalışma istasyonlarından doğrudan elle toplama yöntemi ile temin edilerek Ege Üniversitesi Su Ürünleri Fakültesi Urla Birimine getirilmiştir (Şekil 1). Üzerindeki epifit ve diğer organizmalardan deniz suyu ile yıkanarak temizlendikten sonra dış tanklara kültür çalışmaları için yerleştirilmiştir.

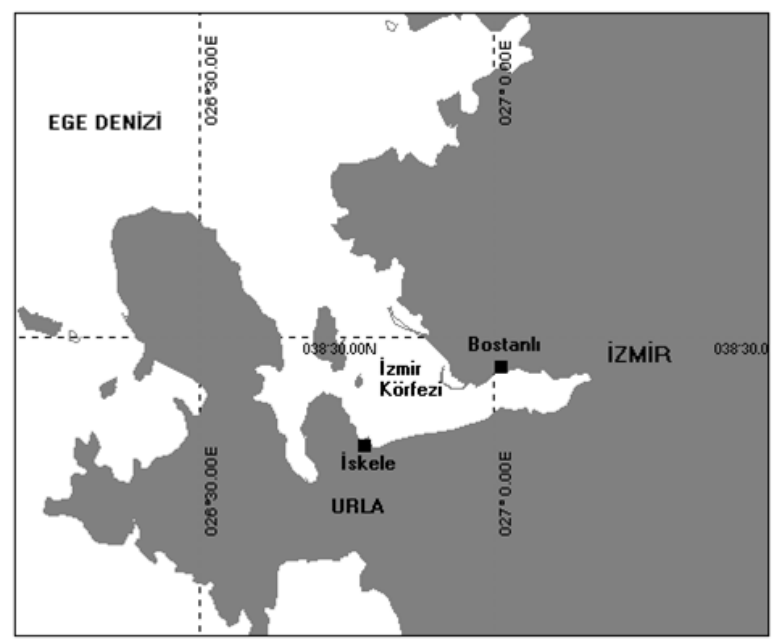

Şekil 1. Makroalglerin toplandığı istasyonlar

Figure 1. Stations where macroalgae were collected

\section{Kültür ortamı}

Kültür ortamı olarak inorganik ticari gübrelerden \% 46 oranında Fosfat içeren Avrupa Gübresi (TSF: Triple Süper Fosfat) ve $\% 26$ oranında azot içeren (\% 13 amonyum nitrojen ve $\% 13$ nitrat nitrojen) ve $\% 12$ oranında kalsiyum içeren Kalsiyum Amonyum Nitrat (CAN) gübresi, her biri bir litrede 1'er gr olacak şekilde zenginleştirilmiş deniz suyu kültür ortamı kullanılmıştır (Ak vd., 2011).

\section{Kültür koşulları}

Makroalg kültürleri denemelerinde $7 \mathrm{~m}^{2}$ yüzey hacmine sahip dairesel polyester kültür tankları kullanılmıştır. Kültür tanklarındaki derinlik $0.5-1 \mathrm{~m}$ olarak ayarlanmıştır. 
Havalandırma ile kültür ortamında sürekli karışım ve pompalar aracılığıyla taze deniz suyu girişi sağlanmıştır.

Kültür tanklarına U. rigida $1 \mathrm{~kg} \cdot \mathrm{m}^{-2}$ (Neori vd., 1991), G. gracilis 0.4 kg.m-2 (Lapointe ve Ryther, 1978; McLachan, 1982) stok yoğunluğunda olacak şekilde yerleştirilmiştir. S. vulgare

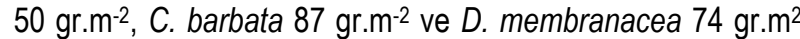
olacak şekilde substratumları ile birlikte kültür tanklarına konulmuştur (Largo ve Ohno, 1993).

\section{Analiz işlemleri}

Laboratuvar koşulları analizler için hazır hale geldiği her bir makroalg türü için minimum 20 adet birey kültür tankından hasat edildikten sonra deniz suyu ile yıkanmış ve mutfak tipi santrifüj yardımıyla üzerindeki su uzaklaştırımıştır. Alg örnekleri kurutma kağıtları ile tekrar kurulandıktan sonra öncelikle laboratuvarda gölgede daha sonra da Etüvde $40{ }^{\circ} \mathrm{C}$ 'nin altında kurutulmuştur. Kurutulan örnekler öğütücüden geçirilerek toz haline getirildikten sonra vitamin analizleri için ayrılarak analizlere başlanmıştır. Analiz işlemleri boyunca hazırlanan alg örnekleri özellikle vitamin kayıplarını önlemek amacıyla $4{ }^{\circ} \mathrm{C}$ ' de buzdolabında koyu renkli amber şişeleri içinde karanlıkta saklanmıştır (Sukatar, 2004).

\section{Vitamin analizleri}

Vitaminler çok çabuk oksidasyona uğrayan maddeler olduğu için kültür koşullarında yetiştirilen alg örnekleri gölgede ve etüvde kurutma işleminden ve öğütücüyle parçalanarak pudra haline getirilme işlemlerinden hemen sonra Provitamin $A$ ( $\beta$-karoten), vitamin $C$ (askorbik asit) ve vitamin $E$ (a-tokoferol) analizleri Urla Birimindeki Plankton Kültürü Laboratuvarı ve Mikro-algal Biyoteknoloji Laboratuvarında yapılmıştır. THALGO firmasının ürettiği mikronize edilmiş alg örnekleri satın alınarak diğer alg örnekleri ile birlikte vitamin analizleri yapıımıştır.

\section{Provitamin A ( $\beta$-Karoten)}

$\beta$-karoten miktarı spektrofotometrik yöntemle bulunmuştur (Zou ve Richmond, 2000). Alg örnekleri spektrofotometrede (Optima SP-300) $475 \mathrm{~nm}$ dalga boyunda $\left(\mathrm{A}_{475}\right)$ okunmuş, $\beta$ karoten miktarının belirlenmesinde kalibrasyon eğrisi hazırlanmıştır. Kalibrasyon eğrisinin oluşturulmasında $\beta$ karoten standardı (\% 95'den daha fazla saflıkta, Sigma Chemical Co., St. Louis, MO, ABD) kullanılmıştır. Bu standart'tan \%0.1'lik $\beta$-karoten Stok çözeltisi hazırlanmıştır. Çalışma Standart Solüsyonları ve Standart Kurveler hazırlandıktan sonra Örnek Çözeltiler hazırlanmıştır (Jensen, 1978; Durmaz, 2005). Spektrofotometre 475 nm absorbans değerine ayarlandıktan sonra referans ile sıfırlanmıştır. Daha sonra örneğin ve standardın absorbansı okunduktan sonra aşağıdaki formülden $\beta$-karoten miktarı $\left(\mathrm{mg.100} \mathrm{ml}^{-1}\right)$ bulunmuştur:

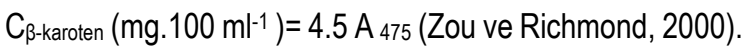

Elde edilen değer mg.100 ml-1 olarak yosun ekstraktı 'nın sahip olduğu $\beta$-karoten miktarını verilmiştir. Bu sonuç toplam yosun örneği için başlangıçtaki toplam yosun ekstraktı miktarıyla çarpıldıktan sonra karşılaştırmaların kolay olması için $100 \mathrm{~g}$ yosun örneği için bulunmuştur.

\section{Vitamin C (Askorbik Asit)}

Vitamin C miktarı spektrofotometrik yöntemle tespit edilmiştir (Hışıl, 2004). Vitamin C miktarının belirlenmesinde kalibrasyon eğrisi hazırlanmış ve kalibrasyon eğrisinin oluşturulmasında vitamin C Standardı (L-Askorbik asit, saflık \% 99, Sigma Chemical Co., St. Louis, MO, ABD) kullanılmıştır. Yüzde 0.4 oranında okzalik asit içeren Stabilizan Çözeltisi ve $\% 0.1$ 'lik askorbik asit içeren Stok Askorbik Asit Çözeltisi hazırlandıktan sonra bu çözeltiden 1, 2, 3, ve 4 mg.100 ml-1 konsantrasyonlarda Çalışma Standart Solüsyonları, boya çözeltisi ve standart kurveler hazırlanmıştır. Hazırlanan örnekler Spektrofotometrede 518 nm 'de okunmuştur. Örneğe ait absorbans değerlerine (Aörnek) karşılık gelen konsantrasyon standart kurveden okunmuştur. Örnek 10 misli seyreltilmiş olduğundan bulunan konsantrasyon 10 ile çarpılmıştır. Sonuç, yosun suyunda mg.100 ml-1 askorbik asit olarak verilmiştir. Elde edilen sonuç toplam yosun örneği için başlangıçtaki toplam yosun ekstraktı miktarıyla çarpıldıktan sonra karşılaştırmaların kolay olması için $100 \mathrm{~g}$ yosun örneği için bulunmuştur (Hışıl, 2004).

\section{Vitamin E (a-Tokoferol)}

Yosun örneklerinin vitamin $E$ içeriği spektrofotometrik yöntemle tayin edilmiştir (Martinek, 1964). Alfa (a)-tokoferol miktarının belirlenmesinde kalibrasyon eğrisi hazırlanmıştır. Kalibrasyon eğrisinin oluşturulmasında a-tokoferol Standardı (\% 95'lik saflıkta, Sigma Chemical Co., St. Louis, MO, ABD) kullanılmıştır. Bu kimyasaldan Stok a-tokoferol Standart Solüsyonu ve Çalışma Standart Solüsyonu hazırlanmıştır. Standart kurve spektrofotometrede çalışma standart solüsyonları ve absorbans değeri ile bir grafik şeklinde oluşturulmuştur. Spektrofotometre $450 \mathrm{~nm}$ absorbans değerine ayarlandıktan sonra referans ile sıfırlandıktan sonra örneğin absorbansı okunmuştur. Okunan değer ekstre edilen toplam karoten değeridir. Ferrik solüsyon tüplere ilave edildikten sonra karıştırımıştır. Spektrofotometre $600 \mathrm{~nm}$ absorbans değerinde referans ile sıfırlandıktan sonra örneğin ve standardın absorbans değerleri okunduktan sonra aşağıdaki formülden Vitamin E miktarı (mg.100 $\mathrm{ml}^{-1}$ ) bulunmuştur:

VitaminE $\quad\left(\mathrm{mg} .100 \mathrm{ml}^{-1}\right)=O ̈$ Ornek $\left(\mathrm{A}_{600}\right)-\quad$ (0.4.Örnek

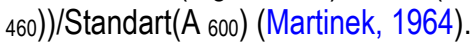

\section{İstatistik analizleri}

Vitamin kompozisyonuna ait veriler SPSS İstatistik Programındaki varyans Analizi ANOVA testi uygulanarak değerlendirilmiştir. Tüm data ortalama \pm standart sapma olarak sunulmuştur. Alg türlerinin vitamin kompozisyonları ortalama değerleri SPSS İstatistik programındaki Tukey'in Çoklu Karşılaştırma Testi uygulanarak karşılaştırılmış ve $P \leq 0.05$ değerleri istatistiki yönden farklı olarak kabul edilmiştir. (Özdamar, 2009). 


\section{BULGULAR}

Ulva rigida, Gracilaria gracilis, Sargassum vulgare, Cystoseira barbata, Dictyopteris membranacea ve THALGO firmasının "mikronize edilmiş algler" olarak üretmiş olduğu ve sağlık ve güzellik merkezlerinde yaygın olarak kullanılan ürün örneklerinin vitamin kompozisyonu belirlemek amaciyla ölçümler yapıımıştır. Analiz sonuçları Tablo 1' de özetlenmiştir.

$\beta$-karoten (provitamin A) yönünden en zengin $3.25 \pm 0.41$ mg.100 g-1 miktarıyla Gracilaria gracilis bulunmuştur. $G$. gracilis'i sırasıyla $1.25 \pm 0.13 \mathrm{mg} .100 \mathrm{~g}^{-1}$ ile $U$. rigida, $0.65 \pm$ $0.05 \mathrm{mg} .100 \mathrm{~g} \mathrm{~g}^{-1}$ ile $D$. membranacea, $0.63 \pm 0.05 \mathrm{mg}^{1} 100 \mathrm{~g} \mathrm{~g}^{-1}$ ile $S$. vulgare, $0.60 \pm 0.05 \mathrm{mg}^{1} 100 \mathrm{~g}^{-1}$ ile $C$. barbata ve 0.05 $\pm 0.00 \mathrm{mg}^{1} 100 \mathrm{~g}^{-1}$ ile THALGO izlemiş̧ir. $\beta$-karoten yönünden $D$. membranacea, $S$. vulgare ve $C$. barbata arasında istatistik yönünden bir fark bulunmazken diğer alg türleri arasında anlamlı bir farklılık bulunmuştur ( $\mathrm{P} \leq 0.05)$ (Tablo 1).

En yüksek Vitamin C (askorbik asit) $7.42 \pm 0.67 \mathrm{mg} .100 \mathrm{~g}$ ${ }^{1}$ olarak U. rigida'da saptanmıştır. Vitamin C, G. gracilis' de 1.12 $\pm 0.33 \mathrm{mg} .100 \mathrm{~g}^{-1}$, C. barbata' da $0.78 \pm 0.08 \mathrm{mg} .100 \mathrm{~g}^{-1}, \mathrm{~S}$. vulgare' de $0.65 \pm 0.05 \mathrm{mg}^{1} 100 \mathrm{~g} \mathrm{~g}^{-1}$, D. membranaceae 'de 0.60 $\pm 0.13 \mathrm{mg} .100 \mathrm{~g} \mathrm{~g}^{-1}$, THALGO'da ise $0.05 \pm 0.00 \mathrm{mg}^{1} 100 \mathrm{~g} \mathrm{~g}^{-1}$ olarak saptanmışıtır. Vitamin $\mathrm{C}$ miktarı yönünden $\mathrm{G}$. gracilis, $\mathrm{C}$. barbata, $S$. vulgare ve $D$. membranacea arasında istatistik yönünden önemli bir fark tespit edilmezken bu türlerin $U$. rigida ve THALGO alg örnekleri ile arasında istatistik yönünden anlamlı bir farklılık bulunmuştur ( $\mathrm{P} \leq 0.05)$ (Tablo 1).

D. membranacea alfa (a)- tokoferol (vitamin E) yönünden en zengin $\left(5.03 \pm 0.12 \mathrm{mg} 100 \mathrm{~g} \mathrm{~g}^{-1}\right)$ alg türü olarak belirlenmiştir. D. membranacea 'yı sırasıyla C. barbata $(3.20 \pm 0.03 \mathrm{mg} .100$ $\left.\mathrm{g}^{-1}\right)$, U. rigida $\left(3.00 \pm 0.05 \mathrm{mgr}^{1} 100 \mathrm{~g} \mathrm{~g}^{-1}\right)$, S. vulgare ( $2.70 \pm$ $\left.0.07 \mathrm{mg} .100 \mathrm{~g}^{-1}\right)$, THALGO $\left(1.5 \pm 0.03 \mathrm{mg}^{1} 100 \mathrm{~g}^{-1}\right)$ ve $\mathrm{G}$. gracilis $\quad\left(1.30 \pm 0.03 \mathrm{mg} 100 \mathrm{~g}^{-1}\right)$ izlemiştir. Alfa (a)-tokoferol düzeyleri yönünden $G$. gracilis ile $U$. rigida ve THALGO, $C$. barbata ile $S$. vulgare, $U$. rigida ve THALGO arasinda istatistiksel olarak önemli bir fark bulunmazken diğer alg türleri arasında önemli bir farklılık bulunmuştur ( $\mathrm{P} \leq 0.05$ ) (Tablo 1).

Tablo 1. U. rigida, G. gracilis, S. vulgare, C. barbata, D. membranacae ve THALGO mikronize edilmiş alglerin vitamin kompozisyonu $\left(\mathrm{mg} .100 \mathrm{~g}^{-1}\right)(\mathrm{N}=3)$ Table 1. Vitamin composition (mg.100 $\mathrm{g}^{-1}$ ) of U. rigida, G. gracilis, S. vulgare, C. barbata, D. membranacae and THALGO micronized algae $(\mathrm{N}=3)$

\begin{tabular}{|c|c|c|c|c|}
\hline Türler & $\begin{array}{l}\text { Provitamin A } \\
\left(\mathrm{mg}^{\left.100 \mathrm{~g}^{-1}\right)}\right.\end{array}$ & $\begin{array}{l}\text { Vitamin A } \\
\text { (IU)* }\end{array}$ & $\begin{array}{l}\text { Vitamin C } \\
\left(\mathrm{mg} 100 \mathrm{~g}^{-1}\right)\end{array}$ & $\begin{array}{l}\text { Vitamin E } \\
\left(\mathrm{mg.100}^{-1}\right)\end{array}$ \\
\hline U. rigida & $1.25^{b} \pm 0.30$ & $2083.75 \pm 500.10$ & $7.42^{\mathrm{a}} \pm 0.67$ & $3.00^{\mathrm{bc}} \pm 0.05$ \\
\hline G. gracilis & $3.25^{a} \pm 0.41$ & $5417.75 \pm 683.47$ & $1.12^{b} \pm 0.33$ & $1.30^{\circ} \pm 0.03$ \\
\hline S. vulgare & $0.63^{b} \pm 0.35$ & $1050.21 \pm 83.35$ & $0.65^{b} \pm 0.05$ & $2.70^{b c} \pm 0.07$ \\
\hline C. barbata & $0.60^{b} \pm 0.20$ & $1000.20 \pm 83.35$ & $0.78^{b} \pm 0.08$ & $3.20^{b} \pm 0.03$ \\
\hline D.membranacea & $0.65^{b} \pm 0.25$ & $1083.55 \pm 83.35$ & $0.60^{b} \pm 0.12$ & $5.30^{\mathrm{a}} \pm 0.12$ \\
\hline THALGO & $0.05^{c} \pm 0.02$ & $83.35 \pm 33.34$ & $0.07^{\circ} \pm 0.03$ & $1.50^{\mathrm{bc}} \pm 0.03$ \\
\hline
\end{tabular}

": ppm olarak belirtmek için $\beta$-karoten (provitamin A) değerleri 2.2 ile çarpılarak veya IU olarak ifade etmek için $\beta$-karoten değerleri 1667 ile çarpılarak ifade edilebilir (AOAC, 1975)

\section{TARTIŞMA VE SONUÇ}

Vitamin analiz sonuçları alglerin $\beta$-karoten (provitamin $A$ ), askorbik asit (vitamin C) ve $\alpha$ - tokoferol (vitamin $\mathrm{E})$ yönünden zengin olduğunu göstermektedir. Makroalglerin zengin vitamin kompozisyonları daha önceki çalışmalarda da vurgulanmıştır (Donadieu ve Basire, 1985; Boisvert, 1988; De RoeckHoltzhauer, 1991). Analizleri yapılan alg türleri arasında $\beta$ karoten (provitamin A) yönünden en zengin $3.25 \pm 0.41 \mathrm{mg} \beta$ karoten.100 g-1 (veya $5417.75 \pm 683.47 \mathrm{IU} .100 \mathrm{~g}^{-1}$ ) miktarıyla G. gracilis bulunmuştur. Önceden yapılan çalışmalarla kıyaslandığında üzerinde çalışılan alg türlerinin diğer türlerin vitamin A kompozisyonuna eş değer veya daha fazlasına sahip olduğu görülmektedir. Laminaria sp.' nin vitamin A içeriği 430 IU.100 g-1, Ascophyllum nodosum' un 58345-13336 IU.100 g ${ }^{-1}$, Porphyra tenera' nın $38400 \mathrm{mg}^{1} 100 \mathrm{~g} \mathrm{~g}^{-1}$, Porphyra yezoensis'in $16000 \mathrm{IU}^{1} 100 \mathrm{~g} \mathrm{~g}^{-1}$, Palmaria palmata' nın $26600 \mathrm{IU}^{1} 100 \mathrm{~g} \mathrm{~g}^{-1}$, Ulva türlerinde 590-960 IU.100 $\mathrm{g}^{-1}$ Enteromorpha prolifera' da 13000 IU.100 g ${ }^{-1}$, Monostroma latissumum' da 2700 IU.100 g- ${ }^{-1}$,
Gracilaria coronopfolia' da 1500 IU.100 g-1 ve Gracialaria salicornia' da 6000 IU.100 g-1 olarak bulunmuştur (McDermid ve Stuercke, 2003). $\beta$-karoten miktarı alg türleri arasında önemli farklııklar gösterir (McHugh, 2003). $\beta$-karoten miktarı kuru $100 \mathrm{~g}$ kahverengi alg için 29-190 mg iken mavi-yeşil algler için 93-408 mg'dır (McDermid ve Stuercke, 2003). $\beta$-karoten miktarı türlere göre farklılık gösterdiği gibi aynı türde mevsimlere göre de farkllık gösterir (Indergaard ve Minsaas, 1991). Kırmızı bir alg türü olan Rhodymenia palmata 'nın $\beta$ karoten miktarı mevsimsel olarak 225 ile $420 \mathrm{mg} \mathrm{kg}^{-1}$ arasında değişir. Genellikle yaz aylarında artan ve kış aylarında azalan $\beta$-karoten miktarı Ascophyllum nodosum için kış aylarında 35 $\mathrm{mg} . \mathrm{kg}^{-1}$ ve yaz aylarında $80 \mathrm{mg}^{\mathrm{kg}}{ }^{-1}$, Fucus serratus için kış aylarında $80 \mathrm{mg}^{\mathrm{kg}}{ }^{-1}$ ve yaz aylarında $185 \mathrm{mg} . \mathrm{kg}^{-1}$ olarak değişir (Indergaard ve Minsaas, 1991).

Bu çalışmada provitamin A olarak sadece $\beta$-karoten içeriği incelenmiş̧tir. Gelecekteki çalışmalarda alglerin toplam karoten değerleri vitamin $\mathrm{A}$ kompozisyonunun tam olarak belirlemek 
için analiz edilmelidir. Önceki çalışmalarda da belirtildiği gibi vitamin A' nın biyolojik değerinin alglerdeki karoten miktarının \% 80-100' üne denk gelmekte ve bu bakımdan alglerin vitamin A değerinin sadece karoten miktarına bağlı olduğu ve karoten miktarından vitamin A değerinin tespit edilmesinin doğru olduğu belirtilmiştir (Atay, 1984).

Vitamin C (askorbik asit) yönünden en zengin $7.42 \pm 0.67$ mg.100 g-1 miktarıyla $U$. rigida bulunmuştur. Daha önceden farklı alg türleri üzerine yapılmış çalışmalarla karşılaştırıldığında bu çalışmada analizlerini yaptığımız alglerin vitamin C kompozisyonlarının düşük olduğunu görürüz. Laminaria sp.' nin vitamin C miktarı 11 mg. $100 \mathrm{~g}^{-1}$, Ascophyllum nodosum' un 55-165 mg.100 g-1, Porphyra tenera' nın 20 mg.100 g g $^{-1}$, Porphyra yezoensis'in 112 mg.100 g-1 , Palmaria palmata' nın 200 mg.100 g-1, Ulva türlerinde 10-12 mg.100 r-1 Enteromorpha prolifera' da $43.2 \mathrm{mg} .100 \mathrm{~g}^{-1}$, ve Monostroma latissumum' da 54 mg.100 g-1 olarak bulunmuştur (Indergaard ve Minsaas, 1991; McHugh, 2003). Türe bağlı olmakla beraber alglerde vitamin C miktarı mevsimlere bağlı olarak da değişmektedir. Norveç'te yetişen kahverengi alglerin vitamin C miktarları kış aylarında en düşük ve ilkbaharda en yüksek olmak üzere Ascophyllum nodosum için $100 \mathrm{~g}$ kuru alg için kış aylarında $65 \mathrm{mg}$ ve ilkbahar aylarında $165 \mathrm{mg}$, Fucus serratus için kış aylarında $60 \mathrm{mg}$ ve ilkbahar aylarında $260 \mathrm{mg}$ ve Fucus vesiculosus için kış aylarında 50 mg ve ilkbahar aylarında 220 mg vitamin C tespit edilmiştir (Jensen, 1966).

Analizleri yapılan alg örneklerinin vitamin C miktarlarının daha düşük miktarda çıkması vitamin C 'nin çevre şartlarından en kolay etkilenen ve hızlı bir şekilde okside olarak biyolojik aktivitesini kaybeden bir vitamin olmasıyla açıklanmıştır. Algler $\% 10$ nem ve $15{ }^{\circ} \mathrm{C}$ sıcaklıkta depolandığında vitamin C' nin yarısı 9 ayda, \% 20 nemde depolandığında ise 7 ayda hepsinin kaybolduğu belirtilmiştir Ayrıca, kurutma, öğütme ve depolama işlemleri sırasında büyük kayıplar ortaya çıkar (Atay, 1984 Pérez vd., 1992; Hoşsu vd., 2005). Ilerdeki çalışmalarda alglerin C vitamini kayıplarını azaltacak olan liyofilizasyon (dondurarak kurutma) gibi yeni kurutma ve basınçla parçalama gibi yeni sistemler kullanılarak algal ürünler hazırlanmalıdır (Donadieu ve Basire, 1985; De Roeck-Holtzhauer, 1991; Sukatar, 2004).

Alfa (a)- tokoferol (vitamin E) yönünden en zengin $5.30 \pm$ 0.12 mg.100 g-1 miktarıyla D. membranacea bulunmuştur. Alglerin vitamin $\mathrm{E}$ içeriği $1-34 \mathrm{mg}^{1}$ 100 $^{-1}$ 'dır (Chapman ve Chapman, 1980). Kahverengi makroalgler içinde vitamin $E$ miktarı en yüksek Ascophyllum ve Fucus türlerinde 200-600 mg tokoferol.kg-1 (kuru ağırlık) olarak bulunmuştur (Chapman ve Chapman, 1980; Indergaard ve Minsaas, 1991). Genellikle Fucus türlerinin kış örneklerinde tokoferol düzeyi yaz

\section{KAYNAKÇA}

Ak, İ., Çetin, Z., Cirik, Ş \& Göksan, T. (2011). Gracilaria verrucosa (Hudson) Papenfuss Culture Using an Agricultural Organic Fertilizer. Fresenius Environmental Bulletin, 20(8a), 2156-2162. örneklerine göre daha yüksektir. Ascophyllum türlerinde ise değişimler daha küçüktür. Vitamin E, ocak ayında en az ve eylül ayında en fazla olmak üzere $100 \mathrm{~g}$ Fucus vesiculosus için ocak ayında $13.8 \mathrm{mg}$ ve eylül ayında $27.2 \mathrm{mg}$, Ascophyllum nodosum için ocak ayında $15.6 \mathrm{mg}$ ve eylül ayında $29.8 \mathrm{mg}$ ve Pelvetia canaliculata için ocak ayında $22.9 \mathrm{mg}$ ve eylül ayında $34.7 \mathrm{mg}$ bulunmuştur (Jensen, 1966).

Kahverengi alglerden Fucus ve Ascophyllum türleri ile karşılaştırıldığında, bu çalışmada alg örneklerimizde bulduğumuz daha düşük vitamin $\mathrm{E}$ miktarı, vitamin $\mathrm{A}$ ve vitamin C için de belirttiğimiz gibi alg pudralarının hazırlanması esnasında kayıplara uğramasıyla açıklanmıştır. Ayrıca, alg unlarının depolanmasında sıcaklık ve nemin az olması istenir. Sıcaklık ve nem alglerin depolanmasında kaliteyi etkiler. Gelecekte yapılacak olan çalışmalarda alglerin vitamin kayıplarını en aza düşürecek olan kurutma ve parçalama işlemleri kullanılarak algal ürünlerin hazırlanması gerekmektedir (Atay, 1984; Pérez vd., 1992; Hoşsu vd., 2005).

Yetiştiricilik koşullarının ve türlerin mevsimsel vitamin içerikleri araştırılarak optimum vitamin depoladıkları zamanlar ve kültür koşulları ayrıca araştııımalıdır. Zengin vitamin kaynakları olan algler Thalassoterapi' nin yanında insan ve havyan gıdası olarak da kullanılabilir.

Sonuç olarak Türkiye sularında içinde ekonomik değeri bulunanların da olduğu 1000 kadar makroalg türü tespit edilmiş olmasına karşılık henüz makroalglere dayalı bir sanayi gelişmemiştir. Zengin makroalg kaynakları özellikle ülkemizin zengin coğrafik ve ekolojik konumundan ileri gelmektedir. Son yıllarda sayıları hızla artan Thalassoterapi ve SPA merkezlerinde kullanılan alg türleri veya eşdeğerleri sularımızda mevcut olmasına rağmen, Thalassoterapi kullanım amaçı bu ürünler yüksek fiyatlardan ithal edilmektedir. Bu sebeple ülkemizde Thalassoterapi'de kullanılmak üzere alg kaynaklarımızın araştırıması kaçınılmaz bir zorunluluktur. Alglerin Thalassoterapi için öneminin yanında insan ve hayvan gıdası, ziraate gübre, eczacılık, kozmetik, tıp, dişçilik, tekstil alanlarında da hammadde ve tamamlayıcı madde olarak değerlendirilmesi üzerinde de çalışmalar yapıımalıdır.

\section{TEŞEKKÜR}

Doktora çalışmasının bir bölümünü oluşturan bu araştırma, Ege Üniversitesi Bilim Teknoloji Uygulama ve Araştırma Merkezi (EBILTEM) Destek Programları altında yer alan "Su Yosunlarının Thalassoterapi'de Kullanımı" isimli proje başlığı ile E04 faslından Proje Oluşturma ve Geliştirme kapsamında desteklenmiştir.

Ak, İ. \& Cirik, S. (2017). Mavi-yeşil algler (Siyanobakteriler) ve termalizm. Ege Journal of Fisheries and Aquatic Sciences, 34(2), 227 - 233

DOI: 10.12714/egejfas.2017.34.2.04 
Atay, D. (1984). Bitkisel Su Ürünleri ve Üretim Tekniği. Ankara Üniversitesi Ziraat Fakültesi Yayınları No: 905, Ankara, 203 sayfa.

Boisvert, C. (1988). Les jardins de la Mer. Du bon usage des algues. Terre Vivante, Paris, Fransa, $157 \mathrm{p}$.

Chapman, V.J. \& Chapman, D.J. (1980). Seaweeds and their uses. London: Chapman and Hall, $334 \mathrm{p}$

Cirik, S. (2005). Denizden Gelen Sağlık. Standart Dergisi. Türk Standartlar Enstitüsünün Ekonomik ve Teknik Dergisi, Su Ürünleri Özel Sayısı, Yayın: 44 , No: $528,47-49$

Cirik, S. \& Turan, G. (2003). Su Yosunlarının Thallassoterapi'de Kullanımı. XII. Ulusal Su Ürünleri Sempozyumu. 2-5 Eylül 2003, Fırat Üniversitesi Su Ürünleri Fakültesi, Elazığ.

Cirik, Ş. (1978) . Recherches sur la vegetation marine de cotes Turques de la mer Egee. Etudes particulieres des peyssonneliacees de Turquie. These, Paris, $172 \mathrm{p}$.

Cirik, Ş., Zeybek, N., Aysel, V. \& Cirik, S. (1988). Note Preliminaire sur la Vegetation Marine de l'ile de Gökçeada (mer Egée Nord,Turquie). Rapp.comm.int. mer, 31, 2-10

Cirik, Ş. \& Cirik, S. (2017). Su Bitkileri: Deniz Bitkilerinin Ekolojisi, Biyolojisi ve Kültür Teknikleri. Ege Üniversitesi, Su Ürünleri Fakültesi Yayınları, No: 58 , Bornova, İzmir, 188 sayfa.

Cirik, Ş., Akçalı, B. \& Bilecik, N. (2001). Gökova Körfezi (Ege Denizi) Deniz Bitkileri. Dokuz Eylül Üniversitesi Yayınları No:09.8888.6000.000 DK.01.001.260. İzmir, 96 sayfa.

Cirik, S.., Ceylan, T., Ateş, A.S., Ak, İ., Büyükateş, Y., Akçalı, B. \& İnanmaz, Ö.E. (2006). Denizi Tanıyalım: Knowing the Marine Environment. ISBN 975-8100-46-7. META Basım matbaacılık Bornova, İzmir, 82 sayfa.

De Roeck-Holtzhauer, Y. (1991). Uses of Seaweeds in Cosmetics. In: Seaweed Resources in Europe: Uses and Potential. Editors, M. D. Guiry and G. Blunden. John Wiley ve Sons, Ltd. England, 83-93.

Donadieu, Y. \& Basire, J. (1985). Les thérapeutiques naturelles: Les Algues Librairie Maloine S.A, Paris, Fransa, $511 \mathrm{p}$.

Durmaz, Y. (2005). Azot Kaynakları ve Konsantrasyonlarının Nannochloropsis oculata (Droop) Hibbert (Eustigmatophycea) 'nin Büyüme ve Biyokimyasal Yapısına Etkisi. (Doktora Tezi). E.Ü. Fen Bilimleri Enstitüsü, Su Ürünleri Yetiştiricilik Ana Bilim Dalı, Bornova, İzmir, 92 sayfa.

Hışı, Y. (2004). Enstrümental Gıda Analizleri: Laboratuvar Deneyleri. Ege Üniversitesi Mühendislik Fakültesi Ders Kitapları yayın No: 45, Bornova, İzmir.

Hoşsu, B., Korkut, A.Y. \& Fırat Kop, A. (2005). Balık Besleme ve Yem Teknolojisi I (Balık Besleme Fizyolojisi ve Biyokimyası). E. Ü. Yayınları,
Su ürünleri Fakültesi Yayın No: 50, Ders Kitabı Dizini No:19, Bornova, İzmir, 276 Sayfa

Indergaard, M. \& Minsaas, J. (1991). Animal and Human Nutrition. In: Seaweed Resources in Europe: Uses and Potential. Editors Michael D. Guiry and Gerald Blunden, John Wiley and Sons, 21-64.

Jensen, A. (1966). Carotenoids of Norwegian Brown seaweeds and seaweed meals. Norwegian Institute of Seaweed Research, Report No: 31: 1-138.

Jensen, A. (1978). Chlorophylls and Catotenoids. In: Hand Book of Phycological Methods. Physiological and Biochemical Methods. Editors Johan A. Hellebust and J. S. Craigie.Cambridge University Press. 512 p.

Lapointe, B.E. \& Ryther, J. (1978). Same aspects of the growth and yield of Gracilaria tikvahiae in culture. Aquaculture 15, 185-93 DOI: $10.1016 / 0044-8486(78) 90030-3$

Largo, D. B. \& Ohno, M. (1993). Constructing An Artificial Seaweed Bed. In: Seaweed Cultivation and Marine Ranching. Editors A. Critchley and M. Ohno. Kanagawa International fisheries Trainin Center, Japan International Cooperatin Agency (JICA), 151 p.

Martinek, R.G. (1964). Method fort the Determination of Vitamin E (Total Tocopherols) in Serum. General Biochemicals. No: 12, Volume10, 10781086.

McDermid, K. J. \& Stuercke, B. (2003). Nutritional composition of edible Hawaiian seaweeds. Journal of Applied Phycology, 15, 513-524 DOI: 10.1023/B:JAPH.0000004345.31686.7f

McHugh, D. J. (2003). A guide to the Seaweed Industry. Food and Agriculture Organization of the United Nations, Roma, Italia, 103 p.

McLachan, J. L. (1982). Inorganic nutrition of marine macroalgae in culture. In: Synthetic and degradative processes in marine macrophytes. Editor L.M. Srivastava, 71-98.

Neori, A., Cohen, I. \& Gordin, H. (1991). Ulva lactuca biofilters for marine fishpond effluents: II. Growth rate, yield and C:N ratio, Bot. Mar., 34: 483489. DOI:10.1515/botm.1991.34.6.483

Özdamar, K. (2009). Paket programlar ve İstatistiksel veri analizleri 1. Kaan Kitapevi, Eskişehir.

Pérez, R., Kaas, R., Campillo, F., Arbault, F. \& Barbaroux, O. (1992). La Culture DesAlgues marines dans Le monde. IFREMER, $614 \mathrm{p}$.

Sukatar, A. (2004). Alg Kültür Yöntemleri. Ege Üniversitesi Fen Fakültesi Kitaplar Serisi No: 184, Bornova. 168 sayfa.

Zou, N. \& Richmond, A. (2000). Light-path lenght and population density in photoacclimation of Nannochloropsis sp. (Eustigmatophyceae). Journal of Applied Phycology, 12, 349-354. DOI: 10.1023/A:100815100 